This is the accepted version of the chapter published in J. C. Richards \& W-M. Roth (Eds.)(2019) Empowering Students as Self-Directed Learners of Qualitative Research Methods. Brill|Sense.

\title{
Living the Praxis of Method, or How I Learned Letting Worldly Practices Organize my Professional Gaze as Scholar
}

Alfredo Jornet

\section{Introduction: A Narrative Inquiry into Gaze Development and Empowerment in Qualitative Research}

Every professional practice can be understood as a particular way of organizing our ways of looking at and seeing the world. For example, where lay people may just see dirt, a professional geologist may see evidence of prior changing climatic conditions in a given area. Similarly, it takes the gaze of an experienced surgeon to see the cystic artery among an otherwise complex of human tissue during surgery (Koschmann, LeBaron, Goodwin, \& Feltovich, 2011), or the gaze of professional aviation pilots to see a particular aviation-relevant situation in and through given cockpit's displays and readings (Roth \& Jornet, 2015). This is what has been coined as professional vision:

discursive practices [that] are used by members of a profession to shape events in the domains subject to their professional scrutiny. The shaping process creates the objects of knowledge that become the insignia of a profession's craft: the theories, artifacts, and bodies of expertise that distinguish it from other professions.

(Goodwin, 1994, p. 606)

In this chapter, I draw from the notion of professional vision to provide a narrative inquiry (Clandinin \& Connelly, 2000) about how, through apprenticeship, I have come to develop a particular way of looking as a qualitative researcher in the domains of education and the learning sciences. I use the narrative inquiry loosely to mean the process by means of which, recollecting events to tell a story, also and at the same time becomes a process of finding out new insights about human experience, here the experience of becoming competent in a particular way of doing qualitative research.

Different methodological approaches involve different ways of organizing one's way of looking and producing (scientific) observations. When Goodwin formulates the idea of professional vision in the terms presented above, he is himself drawing from a particular (phenomenological, pragmatist) way of organizing and perceiving professions as observational objects. This is a tradition in philosophy and sociological inquiry that takes as a premise that "language is veritably man himself in action, and thus observable" (Dewey \& Bentley, 1949/1999, p. 112). It is as part of this historical form of qualitative inquiry, as it lives in current qualitative research in education, that my personal trajectory as apprentice in qualitative research is to be told. But since I begun my trajectory having been educated in a radically different way of crafting scientific observations, this is also a story of conceptual change, of struggle and transformation.

Other chapters in this book describe methods for introducing students to qualitative research practice "at the elbow" of more knowledgeable others (Roth, this volume), supporting them in developing their own voice as researchers (Richards, this volume), thereby positioning students as empowered and self-directed. In this chapter, and through my personal account, I address this issue of empowerment by treating different ways of looking and producing scientific observations as constituting different regimes of power and control, and illustrate how apprenticeship into a particular form qualitative methods - one that takes social practice as primary-was also, and at the same time, a way of becoming empowered as researcher. 
This is the accepted version of the chapter published in J. C. Richards \& W-M. Roth (Eds.)(2019) Empowering Students as Self-Directed Learners of Qualitative Research Methods. Brill|Sense.

\section{A Working Definition}

\section{Empowerment}

At the outset, it is helpful to provide some preliminary definitions, as these have been necessary for me in the process of making sense of my own story about how I came to develop my own professional vision through apprenticeship in qualitative methods. In particular, to tell a story about how I became "empowered," I first needed to understand empowerment as a general process, so that my story could be told as one particular instance or form of expression of such general process. What does it mean, in general and in the context of learning qualitative methods, that one becomes empowered?

To address this question, I draw on teachings from critical psychology, where the issue of empowerment is discussed in terms of agency, defined as "the human capacity to gain, in cooperation with others, control over each individual's own life conditions" (Holzkamp, 2013, p. 20). Particular to this definition, which emphasizes "cooperation with others," is the view of agency as involving an irreducible relation between person and society. This is a view different from that exposed in psychology and learning research in which societal "factors" are included as independent variables that impact individuals' experiences or behaviors, thereby treating society as "merely an environment that has effects upon people" (p. 19). Instead, this is a view that sees the relation between person and environment as the key phenomenon of interest - consistent with the dialectical materialist premise that humans, in contrast to other species, must produce, through labor, the means and conditions for sustaining their own lives ${ }^{1}$.

Becoming empowered, from this perspective, involves not just changing one's own inner mind or psyche (e.g., getting to learn more, or to learn how to learn more on your own). It involves gaining control over the objective (practical, affective, and intellectual) conditions that allow expanding (or restricting) one's opportunities to act, since "the psyche is not merely and individual or inner affair, but the subjective aspect of the way and the degree to which I am in control of the objective conditions of my life" (p. 21).

\section{Empowerment Beyond Restrictive Agency}

Commonly, narratives about empowering students in educational literature tend to be consistent with a discourse that posits learning as some sort of universal process that is somehow independent from a particular content or purpose. This is the case, for example, when empowerment tends to be portrayed in terms of students "owning their educational experience" (Hains \& Smith, 2012, p. 368). From the dialectical perspective defined above, however, this view on empowerment is problematic on two grounds. First, the process of gaining ownership over one's learning tends to be treated a-historically, disengaged from the content and purpose that characterizes the

\footnotetext{
${ }^{1}$ Soviet psychologist Lev S. Vygotsky famously drew on this premise to formulate a general
} genetic law of cultural development, according to which "every function in the cultural development of the child appears on the stage twice, in two planes, first, the social, then the psychological, first between people as an intermental category, then within the child as a intramental category" (Vygotsky, 1997, p. 106). See also Roth, this volume. 
This is the accepted version of the chapter published in J. C. Richards \& W-M. Roth (Eds.)(2019) Empowering Students as Self-Directed Learners of Qualitative Research Methods. Brill|Sense.

cultural-historical practices of knowing and of becoming knowledgeable within the given knowledge domain. However, to discuss how one may become empowered through apprenticeship, requires a consideration of the given cultural-historical practice or profession as part of which one is introduced as apprentice, thereby calling for an epistemology that considers the relation between persons and society as the minimal phenomenon of interest.

Second, by presenting empowerment as a sort of meta-cognitive skill that operates independently from (or only externally connected with) the cultural-historical practices/professions being learned, empowerment is presented as somehow accepting, without critic or struggle, the conditions of and for action inherent in specific practices. From the critical psychology view advanced above, this then is a form of restrictive agency, for it operates by "accepting existing limits in complicity or arrangement ... with prevailing power relations in order to achieve a certain sphere of influence" (Holzkamp, 2013, p. 23). Learners are empowered on the condition that they learn how to learn the given content/praxis autonomously, without regard as to which specific content/praxis this is. In the context of apprenticeship of qualitative research, these would mean getting into a position to freely act with regard to your own learning within the premise that the content that is being learned, as a culturalhistorical practice with its own affordances and conditions for action, is accepted as given, or else, as appropriated in whatever free way the learner has appropriated it.

From this restrictive vision of agency, then, becoming empowered means being allowed leeway to choose conditions for your own learning. But apprenticeship involves, precisely, to be introduced, "at the elbow" of a mentor, and into the historical practice of being/acting/looking as an experimented practitioner. This means introducing learners into ways of looking, acting, and being that are uniquely shaped by reference to and in correspondence with the cultural-historical practices. It also means accepting that becoming an individual subject is only possible in and through becoming the subject of given societal practices. Apprenticeship is but a process of subjectification.

Classical educational and psychological research operate within a restricted view of learning ${ }^{2}$ in which the issue of power and control concerns the way in which the learner relates to her own learning. Apprenticeship, on the other hand, directs our concern on control and power to the historical practice as part of which the learner is introduced. It is in and through understanding to which practices one is introduced and what the emancipating potential of those practices are that one can talk about empowerment through apprenticeship. For one could very well become apprentice of very limiting and disempowering forms of practice, in which case we would not be so willing to talk about empowered learners.

\section{Becoming Empowered in Qualitative Methods}

Once we have a definition of what we mean by empowerment, we are in a position to better understand what becoming empowered in qualitative methods through

\footnotetext{
${ }^{2}$ Gert Biesta has described this way of approaching learning in terms of a learnification of
} education, where broader issues such as the purpose and place of education in society tend to be reduced or ignored all together, in favor of a view of learning as an individualistic concept that is open or empty with regard to content and direction (Biesta, 2010). 
This is the accepted version of the chapter published in J. C. Richards \& W-M. Roth (Eds.)(2019) Empowering Students as Self-Directed Learners of Qualitative Research Methods. Brill|Sense.

apprenticeship may mean in general. If we operate within the premise that agency is not individual and mental, but an objective phenomenon that concerns a relation between the individual person and the societal (collective) labor activities providing the conditions for action and experience, then the process of empowerment must be described by reference to concrete practices, here practices of qualitative research.

It is useful here to come back to the idea of learning qualitative research as a form of developing professional vision, for it assists us in addressing the issue of empowerment as it concerns the specific practice of producing scientific observations - the object that uniquely defines scientific methods - and not just the otherwise widely reported issue of how to get students to self-regulate (e.g., Lapan, Kardash, \& Turner, 2002). Accordingly, becoming empowered as a practitioner of qualitative research methods means gaining control over the conditions by means of which one participates in and gains control over the means by means of which scientific observations are produced.

Since qualitative methods are not homogeneous but can be grouped in terms of different research paradigms, the question may be raised as to how different paradigms of producing scientific observations can be understood as differently allowing learners (as much as experienced practitioners) to gain control over the conditions upon which observations are produced and competence developed. Rather than addressing these questions in the abstract, however, I explore them as I proceed narrating my story. For, as I advance in the introduction, this is a story of paradigm change, of how I learned to develop a professional vision despite having started from a very different way of looking at things. Specifically, mine is the story of becoming empowered in and through being immersed, at the elbow of a more experienced practitioner, away from a formalistic approach to methods, and into a dialectical, pragmatist, and phenomenological way of looking at and for scientific facts.

\section{My Story of Growth and Empowerment, in Two Chapters}

In the following, I present a narrative that speaks about my own personal growth into qualitative research methods. Because this is a story of personal transformation and empowerment told from the perspective of the learner, I have chosen to present it in terms of a shifting subjectivity and expanding agency. A first chapter describes a period during which, after having been trained in a (formal) way of looking at and for data, I struggled to find relevance and to shift into a different paradigm. The second chapter speaks about the lived-through process by means of which I got to emancipate from the formal paradigm and into a different regime of producing observations.

Although the narrative concerns my own personal development, in telling it, I also insert vignettes about other students who, although having their own personal stories and trajectories, can be seen and listened to as the subjective sides of an objective reality that cannot be reduced to either individuals or societal contexts. Thus, the first chapter starts with vignettes depicting very recent events, and where I appear as the more knowledgeable other who already is competent in a particular way of doing qualitative research. Yet, in bringing these vignettes up front as a way in into my own personal story of growth, my hope is to help readers see my personal struggle and process of growth not as my own, but as one possible expression of what it means, in general, being a learner of qualitative research methods.

\section{Two Vignettes}

\section{Chapter 1: Being Subjected to Formal Methods}

Vignette 1. I am at my office writing the introductory sections of this chapter when a recently admitted $\mathrm{PhD}$ student (student $\mathrm{A}$ ) knocks at my door and asks whether I have 15 minutes to talk. I do. I invite her in and ask her what she wonders 
This is the accepted version of the chapter published in J. C. Richards \& W-M. Roth (Eds.)(2019) Empowering Students as Self-Directed Learners of Qualitative Research Methods. Brill|Sense.

about. She begins talking about being aware that I am familiar with the work of a particular scholar who had developed a theoretical concept that she might use in her dissertation. I ask what her dissertation is about - I do not supervise her-and she mentions that it has to do with how teacher education students use digital resources as part of their praxis. But she quickly moves back to her concern, which revolves around her having difficulties to understand a concept. She finds that different authors seem to have different ways of formulating or understanding the concept and she wants to make sure that the understanding she has of the concept is correct, or perhaps the correct one. This is important for her since, as she explains, she needs to understand the concept to be able to formulate her research question. She is distressed about this, she adds, because she is unsure about what she is going to make her investigation, data collection, etc.

I ask why she needs to understand this concept before formulating her research question, and why she is so nervous about getting the concept right at this stage. I explain to her that, although I am to some extent familiar with the authors and concepts that she is talking about, I would rather talk about why she feels that way about getting the concepts right. I tell her that rather than being nervous about what a given concept means, she might benefit from more carefully considering the problem of practice - of teacher students practice and their use of technology - she wants to address. I explain how the purpose of our research must somehow address the purposes of the investigated practices and that therefore it makes little sense to take as point of departure a concept or theoretical definition. Instead, she should take the problems of practice as the starting point, and then find how any given concepts can help address those problems. I tell her that she does not need to feel that she is at the service of the concepts, but that concepts should be put at the service of the practices she wants to study. She engages emotionally in the conversation, expresses relief and tells me, "these have been the most fruitful 15 minutes of her PhD so far."

Vignette 2. Recently, I have accepted becoming co-supervisor of a student (student B), who has gone through personal difficulties that have prevented her from advancing her work during the last months. Her scholarship period is getting close to an end, period after which she will have to come back to her country of origin, where there will be restricted opportunities to continue advancing her thesis.

The first task that we work on is revising an article she has been writing, about what she has termed professional identity in the context of teacher education in her country. Through the paper, the student aims to document how mentor-mentee relations as part of the students' praxis, contribute to establishing the students' "professional identity." She shows me the interviews she collected as data, which document interviews between mentors and teacher student after their first day of praxis, and here analyses thereof. In her presentation, she had identified a number of findings in the form of categories that then are substantiated with excerpts from interviews, quotations from the informants, and other ethnographic materials (Figure 1). I immediately observe a mismatch between her claims concerning the findings, which she highlights in the section's sub-headings, and the actual empirical data that she presents and supposedly analyses.

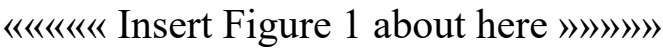

In the extract, the title refers to an action, "establishing roles and responsibilities" (Figure 1). However, upon looking at the excerpt that follows, I cannot see how the excerpt is exhibiting "establishing roles and responsibilities." In the text that follows, 
This is the accepted version of the chapter published in J. C. Richards \& W-M. Roth (Eds.)(2019) Empowering Students as Self-Directed Learners of Qualitative Research Methods. Brill|Sense.

where I would have expected to read the analyses that would make visible how the excerpt instantiates the category, I find brief observations that, while making brief reference to some of the lines in the excerpt, do not seem to be about "establishing roles and responsibilities." I then understand how the categories the student is arriving at are intended to describe relevant dimensions of the teacher profession, but that how these categories exist as interactional ${ }^{3}$ objects of concern for the participants, is not specified. A gap exists between the abstract categories being presented as findings, and the empirical observations, which are presented only briefly, as if the abstract categories were what one could "see" directly in the excerpt, and therefore the analysis was unnecessary. I explain to the student, that she needs to pay more attention to the concerns and orientation of her participants. I ask her, "do you think that if, during the moment of the interview, if you had asked to the participants, "what are you doing now?', they would have answered, 'yes, we are establishing roles and responsibilities'?" She says no, and I invite her to return to the analyses together.

\section{Competences of Professional Seeing, Now and Then}

The two vignettes above present two situations that I have experienced recently while being the "more knowledgeable other." They document, among other things, the fact that I find myself now in a position where I can see things that those who are at an earlier stage in their career — as I was just a few years ago - cannot. But that is not to say that they do not have competences to see things. In fact, it would be a mistake to assume that these students simply do not see or have trouble seeing, for they do see things. They do exhibit a competence of seeing (in the second vignette) or of searching for things to be able to see (in the first vignette) that is not to be disregarded. Their competence of seeing is different than mine not so much because they do not have as much experience as I. Rather, the difference lies in the fact that their gaze is grounded in a way of understanding the production of scientific observations that is fundamentally different to the way I look at and for things when doing research.

Common to both vignettes above - and they are only two examples of what I experience on a regular basis when it comes to students having troubles with getting their analytical work done - is a way of understanding qualitative analysis as the abstraction of general, formal categories. Analysis, from this view, is a form of abstraction. And, formally - as known by all students and experienced researchersthere are two possible paths to abstraction: induction (the seeking of categories by abstracting formal commonalities among multiple empirical instances) and deduction (the making sense of empirical data and phenomena by taking some abstract category or concept as the point of departure). It is possible from this perspective, then, to see how student $A$ in vignette 1 is working on deductive premises, and student $B$ in vignette 2 is working on the premises of induction.

When I begun my $\mathrm{PhD}$ studies, took the formal paradigm as the point of departure. Having been educated in a quantitative, psychometric paradigm, psychological categories were observable to me in terms of frequency and regularity. That is the idea of pattern within which I operated, even before I could articulate it in adequate

3 Throughout this chapter, I use the notion interaction, or social interaction, in order to make the reading accessible to a wider readership. However, by interaction I do mean a very specific 
This is the accepted version of the chapter published in J. C. Richards \& W-M. Roth (Eds.)(2019) Empowering Students as Self-Directed Learners of Qualitative Research Methods. Brill|Sense.

declarative form (as in a definition) dominated how I approached qualitative research. It was when I attempted to shift into a qualitative paradigm that I realized how deeply entrenched this old paradigm was in my language, in my orientation, in my way of being. I was a living reality of the way a research paradigm exists as an objective, but organic fact of scholar life.

I remember reading L. S. Vygotsky, G. H. Mead, J. Dewey and G. Bateson, and doing my best to intellectually understand what they were writing. I read, for example, that pattern need not be understood in the formalistic way described above, but rather as the way in which living, organic creatures, as well as inorganic elements, are connected with each other in real, objective life (Bateson, 1979). I did read about the pattern that connects, as Bateson refers to it, which was not the outcome of abstraction but was the outcome of real genesis and development of forms. Analysis, then, is not abstraction, but the seeking after the real, organic connections that hold things, events, and lives, together in genetic and historical connection (Ilyenkov, 1977). I could understand that.

Apparently, I could not implement such understanding in my actual way of conduct. For every time I tried to perform analyses of the video recordings, interviews, and other qualitative materials I had collected, my mentor would point out: you are still looking for abstractions, not for real, social phenomena. Intellectually, I felt I understood what that meant. But I failed again and again to implement the declarative premises as an actual program for action. Just as students A and B above, I felt deeply frustrated, specially at the beginning, when my ways of orienting for and towards information in my empirical materials, was so much intertwined with a formal, individualistic way of approaching social and psychological phenomena. I recall my mentor telling me something like: "if you want to go inside the head of individuals, and try to do an analysis from an individualist perspective, that is fine. Just be explicit about it, and do it. But if you really want to do the type of analysis you are saying you are doing-qualitative analyses of social interaction - then you need to get at the real social relation. What is it going on from the perspective of the participants?" (my recall).

At that time, I, like students A and B, was subjected to a particular way of looking that required me to comply with a rigid way of extracting information in a way that did require to explicitly and purposefully ignore the concrete, messy and apparently uninteresting, self-evident reality of the people involved in the practices I wanted to study. Becoming "free" or gaining agency in that type of doing research meant to comply with the premise of abstraction, along with that of the existence of psychological categories that were general and abstract, yet individual and mental. To gain control over the conditions for producing scientific observations meant to control formal methods of analysis. But those methods were in conflict with the historical practice into which my mentor was introducing me. There, becoming empowered meant something different, and I needed to change my ways of looking.

\section{Chapter 2: Becoming the Subject of Qualitative Methods}

Vignette 3. In the vignette here described, it is my first year during my postdoc. At this point, I have gone through four intense years of crafting an article-based $\mathrm{PhD}$ thesis in which I have come to master qualitative methods of analysis to some degree of autonomy. A most relevant part of my formation has been to have been introduced to co-authoring written empirical studies, and having been included as core participant in research data sessions as the ones described in Roth (this volume). All of the later have shaped my ways of looking at and for data in very important ways. But of course, during my first year of postdoc - and hopefully at any point in my 
This is the accepted version of the chapter published in J. C. Richards \& W-M. Roth (Eds.)(2019) Empowering Students as Self-Directed Learners of Qualitative Research Methods. Brill|Sense.

career trajectory-I still feel I have lots to learn. Particularly, I still and frequently struggle to get at the social core of the phenomena I research, and to find the relevance in the practices, rather than in the theories or conceptual predispositions that I bring to the research.

A turning point, however, took place during a period in which I begun to be more and more aware of the changes I had been experiencing with regard to my competence of seeing relevance and quality when observing and reflecting upon social interactions (i.e., during video data sessions). In the situation described here, I am participating as a student and assistant during one of the seminars on rigorous data analysis, in which students are given the opportunity to share pieces of empirical data for joint analysis (Roth, this volume). In particular, I am joining a group of $\mathrm{PhD}$ students who are discussing haiku - a short form of Japanese poetry-as a form and asset for mindfulness in education.

The leading student has presented as data an interview that she has found online and which involves a journalist or media person as interviewer, and an artist with a long trajectory of writing haiku. We are analyzing the interview, discussing the ways in which both haiku and mindfulness are treated and taken up in the discussion as concepts and concerns, as well as examining the rigor of our claims about the text. I realize then that, while we are discussing these issues on haiku and mindfulness, we are in fact enacting some of the same competences and social interaction structures that the participants in the interview are enacting. I further become aware of how we are not only enacting some common characteristics or attributes, which one could abstract from both the interview and our discussion; though this might also be possible. ${ }^{4}$ I mean, we are not just talking the same language, and using similar wordings, or even gestures, as the participants in the interview are doing. Rather, we are enacting similar competences in that, in taking up and engaging with haiku as a practice-we have been in fact going through haiku's formal structure of verses, have used it, referred to it in our conversation - we somehow are partaking in haiku as a real historical object. The same object that motivates the interview we analyze, as a concrete and social way of orienting, was motivating and orienting our conversation. It was just doing so in a different context and leading to different experiences and insights, but really the living praxis of doing and thinking about haiku.

\section{Living the Praxis of Qualitative Method}

I recall this particular vignette here for I experienced it as part of a larger moment in my career in which seeing the relevance and structure of social phenomena begun to feel like something transparent; no longer a struggle, but rather an embodied and immediate way of being, or of living the praxis of method. I indeed began to feel free when confronting data and, actually, I not only felt free but also felt deeply motivated to go into analyzing any and every material of social relevance in my hands.

\footnotetext{
${ }^{4}$ As a researcher, I realize of the usefulness and importance of formal methods,
} even though I hold it that quality, as in qualitative research, is not about abstract form but as forms of organic, developmental, ecological relations (Jornet \& Damsa, in press). 
This is the accepted version of the chapter published in J. C. Richards \& W-M. Roth (Eds.)(2019) Empowering Students as Self-Directed Learners of Qualitative Research Methods. Brill|Sense.

This became visible in our data analysis sessions (see Roth, this volume), in which my mentor and I would meet with other participants, both internal and external to our research lab, and would perform initial analyses together. It became a routine that both my mentor and I would take no longer than a few minutes to begin establishing the relevance and content of the social phenomena we were observing. This was the case to such an extent that, after the sessions some of the individuals present contacted me even though they had a higher rank and longer experience than I. They asked me for advice about how to see all the things we saw in the participants' data. Our finding of the relevance and content occurred independently of the type of setting that we were presented with, as long as the data would exhibit concerted practices. We would just observe, attend, with care, to the ongoing interactions. That is all we needed to do. Relevance was there in the setting for us to see, for I- as my mentor had before me- had learned to let the worldly, social practices we attended to guide my gaze and show me what the relevance of the setting was. This relevance, then, was not the product of an inductive abstraction, for it was firmly anchored in experiencing, as close as possible, the very concrete, social situations that the data presented us with. It was not the outcome of deduction either, for no abstract concept would have anticipated the given events that we were to observe. Relevance was there for us to see and document, for relevance was in and of the social phenomena we were studying.

This competence to let our gaze be guided and correspond with the social phenomena that we aimed to understand was, I gather, the competence that allowed us to come up with many insights and possible lines of inquiry. There are always too many interesting arising so my next lesson to learn - and which I am still learning today - is to follow one object among the many possible objects that can be of interest in and for education. But going into that would be a next chapter to this story-a chapter on purpose and choice in qualitative research — which goes beyond what I had set to discuss here.

\section{Concluding Remarks}

In this chapter, I present a narrative account of how, through apprenticeship in the praxis of qualitative research, I grew into a qualified scholar who now feels autonomous and knowledgeable in the field. Today, I guide students and colleagues, teach courses on qualitative research methods, and initiate students into qualitative research using the same apprenticeship approach that my mentors used with me.

Becoming a competent qualitative methods researcher through apprenticeship was, in my case, a case of shifting and developing a professional vision, a form of looking at and for scientific observations about social learning phenomena. The metaphor of professional vision is important because it highlights both the embodied, affective, and cultural character of the process. As described above, being told about theory and methods would not have been enough. Developing a lived and living sense of the significance and implications of doing qualitative research involved getting vitally involved in a process of correspondence with the sort of phenomena that become visible when one takes the non-reductionist perspective described throughout this chapter.

I use the term correspondence to describe the relation between observer and world (between scientist and the object of her research) in a way in which the world, here the social world, does not stand outside as a thing to explore without being changed by exploring it. Professional vision then is understood as an organic, intellectual, affective, and practical process of being with rather than outside or against the social world. As it has been said in anthropological research, citing Goethe, "to see the sun 
This is the accepted version of the chapter published in J. C. Richards \& W-M. Roth (Eds.)(2019) Empowering Students as Self-Directed Learners of Qualitative Research Methods. Brill|Sense.

... the eyes must already respond to its light. But conversely, the sun can only shine in a world with eyes capable of so responding. Eyes and sun thus co-respond" (Ingold, 2015 , p. 98). Just in the same way, becoming a competent researcher in qualitative research through apprenticeship is a process of coming to correspond with one's own objects of research in a way in which observing is also a form of being transformed.

Several of the chapters in this volume document different teaching and learning practices that lead to empowerment in and through learning qualitative methods. In this chapter, and as part of my efforts to make sense of my own narrative, I further specify a particular approach to understanding empowerment that takes the nonindividualist, dialectical materialist premise that agency or power to act is determined by achieving control of the means of production of given cultural-historical practices. From this perspective, and as I have illustrated throughout my narrative, becoming empowered through apprenticeship cannot be disentangled from the cultural practices in which one is introduced and positioned as apprentice.

In my narrative, I describe how different methodological paradigms offer different opportunities for gaining control over the means and conditions that allow producing scientific observations. Formal approaches require of learners (and professionals alike) to comply with specialized methods of observations that are designed to abstract formal analytical categories from empirical phenomena in ways that do let the methodology of observation unchanged. Whereas becoming competent in such research can be productive and necessary for multiple research purposes, as a praxis of seeing and of producing observations, it also constitutes a form of restrictive agency (Holzkamp, 2013). Many students, like the ones mentioned here, can find such experience restricting.

Gaining control over the means for producing observations in the qualitative paradigm in which I have been trained - one that aligns with the pragmatist, dialectical materialist, and phenomenological literature cited through this chapterrequires joining and coming to terms with the social objects one aims to study in ways that cannot be pre-established or fixed by given methods. ${ }^{5}$ Empowerment here means being capable of joining cultural practices and ways of seeing the world, with the consequent possibility of emancipation (and capacity to empower others) that this relation with social objects entails.

\section{References}

Bateson, G. (1979). Mind and nature. A necessary unity. New York, NY: E. P. Dutton.

Biesta, G. (2010). Good education in an age of measurement. Ethics, politics, democracy. Abington: Routledge.

Clandinin, D. J., Connelly F. M. (2000). Narrative inquiry: Experience and story in qualitative research. San Francisco, CA: Jossey-Bass.

Dewey, J., \& Bentley, A. F. (1999). Knowing and the known. In R. Handy \& E. E. Hardwood (Ed.), Useful procedures of inquiry (pp. 97-209). Great Barrington:

Behavioral Research Council. (First published in 1949)

Garfinkel, H. (1967). Studies in ethnomethodology. Englewood Cliffs, NJ: PrenticeHall.

${ }^{5}$ This is most explicitly stated in ethno-methodology, or the study of methods ordinary "people" use in making society visible (Garfinkel, 1967). 
This is the accepted version of the chapter published in J. C. Richards \& W-M. Roth (Eds.)(2019) Empowering Students as Self-Directed Learners of Qualitative Research Methods. Brill|Sense.

Goodwin, C. (1994). Professional vision. American Anthropologist, 96(3), 606-633.

Hains, B. J., \& Smith, B. (2012). Student-centered course design: Empowering students to become self-directed learners. Journal of Experiential Education, $35(2), 357-374$.

Holzkamp, K. (2013). Basic concepts of critical psychology. In E. Schraube \& U. Osterkamp (Eds.), Psychology from the standpoint of the subject. Selected writings of Klaus Holzkamp (pp. 19-27). Houndsmills: Palgrave Macmillan.

Ilyenkov, E. V. (1977). Dialectical logic. Essays on its history and theory. Moscow, RU: Progress Publishers.

Ingold, T. (2015). The life of lines. Abingdon, UK: Routledge.

Jornet, A., \& Damsa, C. (in press). Unit of analysis from an ecological perspective. Beyond the individual/social dichotomy. Learning, Culture, and Social Interaction.

Jornet, A., Roth, W-M., \& Krange, I. (2016). A transactional approach to transfer episodes. Journal of the Learning Sciences, 25, 285-330.

Koschmann, T., LeBaron, C., Goodwin, C., \& Feltovich, P. (2011). "Can you see the cystic artery yet?" A simple matter of trust. Journal of Pragmatics, 43, 521-541.

Lapan, R. T., Kardash, C. A., \& Turner, S. (2002). Empowering students to become self-regulated learners. Professional School Counseling, 5, 257-265.

Roth, W-M., \& Jornet, A. (2013). Situated cognition. WIREs Cognitive Science, 4, 463-478.

Roth, W-M., \& Jornet, A. (2015). Situational awareness as an instructable and instructed matter in multi-media supported debriefing: A case study from aviation. Computer Supported Cooperative Work, 24, 461-508.

Vygotsky, L. S. (1997). The collected works of L. S. Vygotsky vol. 3: Problems of the theory and history of psychology. New York, NY: Plenum. 
This is the accepted version of the chapter published in J. C. Richards \& W-M. Roth (Eds.)(2019) Empowering Students as Self-Directed Learners of Qualitative Research Methods. Brill|Sense.

\section{Establishing roles and responsibilities}

Mentor: What else did you do to make your lesson successful? I was enjoying. I stopped writing. I wished you could say this, and it could happen.

Mentee 2: You have to plan. You have to design the instructional materials that match with the content. You have to aim at the intellectual competences

Mentor: Very true! What were the competences of today?

Mentee 2: They had to identify the letter sound, to know its action, give other letters with the same sound, to know the written form (capital \& small) and its application e.g. beginning of a name of a person, a sentence

Mentor: I saw that it was done. What else did you do excellently?

Figure 1. Extract from a PhD student's draft, published here with permission of the student. 